\title{
Lossy/Lossless Grounded Inductance Simulators Using Current Feedback Operational Amplifier (CFOA)
}

\author{
Muhammed Emin Başak' (D), Fırat Kaçar² \\ 'YıldızTechnical University School of Naval Architecture and Maritime, İstanbul, Turkey \\ ${ }^{2}$ Department of Electrical and Electronics Engineering, İstanbul University School of Engineering, İstanbul, Turkey
}

Cite this article as: E. Başak, F. Kaçar. "Lossy/Lossless Grounded Inductance Simulators Using Current Feedback Operational Amplifier (CFOA)". Electrica, vol. 18, no. 1, pp. 95-99, 2018.

\section{ABSTRACT}

Active elements are critical in implementing active filters, oscillators, rectifiers, and signal processing circuits. We observe that several active circuits have been proposed in the literature. In this study, we have proposed four inductance simulators that employ only one active circuit current feedback operational amplifier and three or four passive components. The first and fourth topologies are designed for series lossy inductance, whereas the second and third topologies are designed for lossless negative inductance simulators. A passive RLC filter is used to demonstrate the effectiveness of the proposed inductance simulators. The simulations performed with the LTSpice program and the results agree with the theoretical analysis.

Keywords: CFOA, filter, CMOS

Address for Correspondence:

Muhammed Emin Başak

\section{E-mail:}

mebasak@yildiz.edu.tr

Received: 07.11.2017

Accepted: 04.01.2018

(c) Copyright 2018 by Electrica

Available online at

http://dergipark.gov.tr/iujeee

DOI: 10.5152/iujeee.2018.1815

\section{Introduction}

Inductance is the source of many problems in electronic circuits and systems. It stands to reason that inductance radiates magnetic energy, it places a larger footprint in the integrated circuit, and it contains more parasitic noises than other components. Bulky and expensive passive inductors motivated the researchers to design the alternative circuits can be worked as inductors. Inductance simulators are widely used, especially for high frequencies, instead of inductors. Therefore, for designing filters or oscillator, for eliminating electromagnetic interferences the inductance simulators are used.

Recently, a considerable literature has grown up the theme of active inductance realization. Several active inductance simulators have been proposed such as operational transconductance amplifier (OTA) [1-3], operational transresistance amplifier (OTRA) [4,5], current-feedback operational amplifier (CFOA) [6-12] current differencing buffer amplifer (CDBA) [13,14], four terminal floating nullor (FTFN) [15], voltage differencing buffer amplifer (VDBA) [16-18], differential voltage current conveyor (DVCC) [19], second generation current conveyor (CCII) $[20,21]$, dual-X current conveyor (DXCCII) [2224]. Most of the reported circuits are commercially unavailable such as OTRA, CDBA, DVCC, DXCCII. Some of them such as FTFN [15] can be realized using two active devices such as AD844 CFOA can be commercially available. CFOA is a low-cost, general purpose device that has good $A C$ and DC performance. CFOA is current mode circuit so it has some inherantel advantages over the voltage mode operational amplifers such as wider bandwidth, wider dynamic range and greater linearity. It also allows high slew rate capability and it is free from the slew rate boundries that are basic characteristics of the traditional operational amplifiers. 
Four different inductance simulators employing a single CFOA and three or four passive components were presented in [6]. Three different generic structures were also presented in [11] which employing a single CFOA and three or four passive components. The circuits [25-27] are not operated commercially available devices such as AD844, LM741. The circuits [4,28-31] can be constructed with more than one AD844.

The overall structure of the study takes the form of four sections. The first section is an introduction, the second section gives the proposed four grounded inductance simulator topologies and parallel resonant circuit is constructed with the proposed inductance simulator, the third section gives the simulation results and the last section is the conclusion. It is expected that the proposed circuit will provide different opportunities to the designers accomplishing of analog integrated circuit applications.

\section{The Proposed Inductor Simulators}

The equivalent circuit of CFOA is shown in Figure 1. In the ideal case, current gain and voltage gains are $\alpha=1$ and $\beta_{1}=\beta_{2}=1$, respectively. So; CFOA whose electrical symbol ideally specified as $\mathrm{I}_{\mathrm{y}}=0, \mathrm{I}_{\mathrm{z}}=\mathrm{I}_{\mathrm{x}^{\prime}} \mathrm{V}_{\mathrm{x}}=\mathrm{V}_{\mathrm{y}}$ and $\mathrm{V}_{\mathrm{w}}=\mathrm{V}_{\mathrm{z}^{\prime}}$ are going to be stated by the following equation:
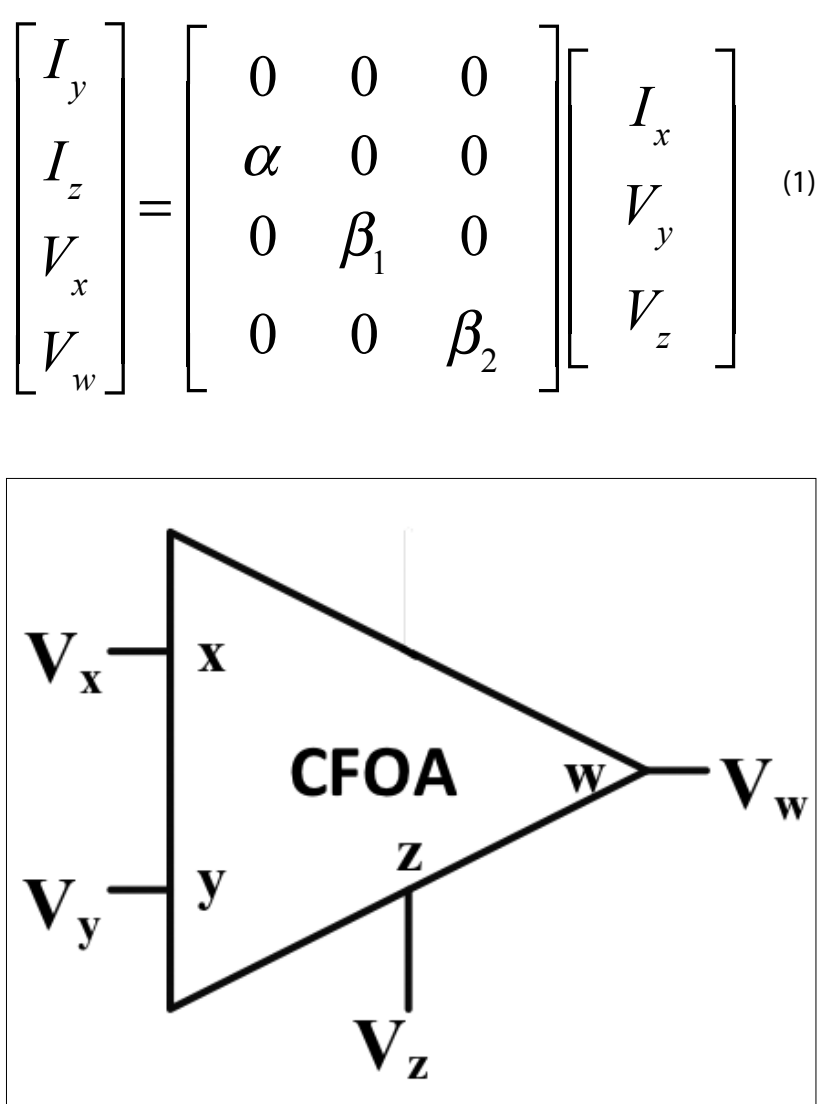

Figure 1. Equivalant circuit of CFOA
Table 1. Equivalent impedances of proposed inductance simulators

\begin{tabular}{lcc}
\hline Circuit & $\begin{array}{c}\text { Non-ideal } \\
\text { impedances }\left(\mathbf{Z}_{\text {eq }}\right)\end{array}$ & $\begin{array}{c}\text { Ideal impedances } \\
\left(\mathbf{Z}_{\text {eq }}\right)\end{array}$ \\
\hline Figure 2 (a) & $\begin{array}{l}\frac{R_{1}}{1+C s \alpha(\gamma-\beta) R_{2}}+\frac{R_{2}}{1+C s \alpha(\gamma-\beta) R_{2}} \\
+\frac{C s \alpha \gamma R_{2}}{1+C s \alpha(\gamma-\beta) R_{2}}\end{array}$ & $R_{1}+R_{2}+C s R_{1} R_{2}$ \\
\hline Figure 2 (b) & $-\frac{C R_{1} R_{2} s}{\beta \gamma+C R_{2} s(-1+\beta \gamma)}$ & $-C R_{1} R_{2} S$ \\
\hline Figure 2 (c) & $\frac{C_{2} R_{1} R_{2} s}{C_{2} R_{2} s-\alpha \beta \gamma-C_{1} R_{2} s \alpha \beta \gamma}$ & $\frac{C_{2} R_{1} R_{2} s}{-1-C_{1} R_{2} s+C_{2} R_{2} s}$ \\
\hline Figure 2 (d) & $\frac{R_{1}}{1-C s(-1+\alpha \beta \gamma) R_{2}}+\frac{C s R_{1}}{1-C s(-1+\alpha \beta \gamma) R_{2}}$ & $R_{1}+C s R_{1} R_{2}$ \\
\hline
\end{tabular}

Table 2. Equivalent admittances of proposed inductance simulators ideal and non-ideal cases

\begin{tabular}{lcc}
\hline Circuit & $\begin{array}{c}\text { Non-ideal } \\
\text { admittances }\left(\mathbf{Y}_{\mathbf{e q}}\right)\end{array}$ & $\begin{array}{c}\text { Ideal admittances } \\
\left(\mathbf{Y}_{\text {eq }}\right)\end{array}$ \\
\hline Figure 2 (a) & $\frac{1}{R_{1}+R_{2}+C \operatorname{cs} \alpha R_{1} R_{2}}+\frac{C s \alpha(-\beta+\gamma) R_{2}}{R_{1}+R_{2}+C s \alpha \gamma R_{1} R_{2}}$ & $\frac{1}{R_{1}+R_{2}+C s R_{1} R_{2}}$ \\
\hline Figure 2 (b) & $-\frac{\beta \gamma}{C R_{1} R_{2} S}+\frac{1-\beta \gamma}{R_{1}}$ & $-\frac{1}{R_{1} R_{2} C s}$ \\
\hline
\end{tabular}

Figure 2 (c) $\quad \frac{1}{R_{1}}-\frac{C_{1} \alpha \beta \gamma}{C_{2} R_{1}}-\frac{\alpha \beta \gamma}{C_{2} R_{1} R_{2} s} \quad \frac{1}{R_{1}}-\frac{C_{1}}{C_{2} R_{1}}-\frac{1}{C_{2} R_{1} R_{2} s}$

Figure $2(d)$

$$
\frac{1}{R_{1}+C s R_{1} R_{2}}+\frac{C s(1-\alpha \beta \gamma) R_{2}}{R_{1}+C s R_{1} R_{2}} \quad \frac{1}{R_{1}+C s R_{1} R_{2}}
$$

The proposed CFOA based inductor simulators are shown in Figure 2 a-d. The first inductance simulator consists of one CFOA and three passive components while the others consist of one CFOA and four passive components. Transfer functions of the proposed circuits are given in Table 1, 2. According to the equivalent impedance of the first and fourth simulators are intended for lossy series inductors. The second simulator is intended to negative lossless inductance simulator. The third one is also intended to negative lossless inductance simulator if $C_{1}$ and $C_{2}$ capacitors and $R_{1}$ and $R_{2}$ resistors are equal to each other. 

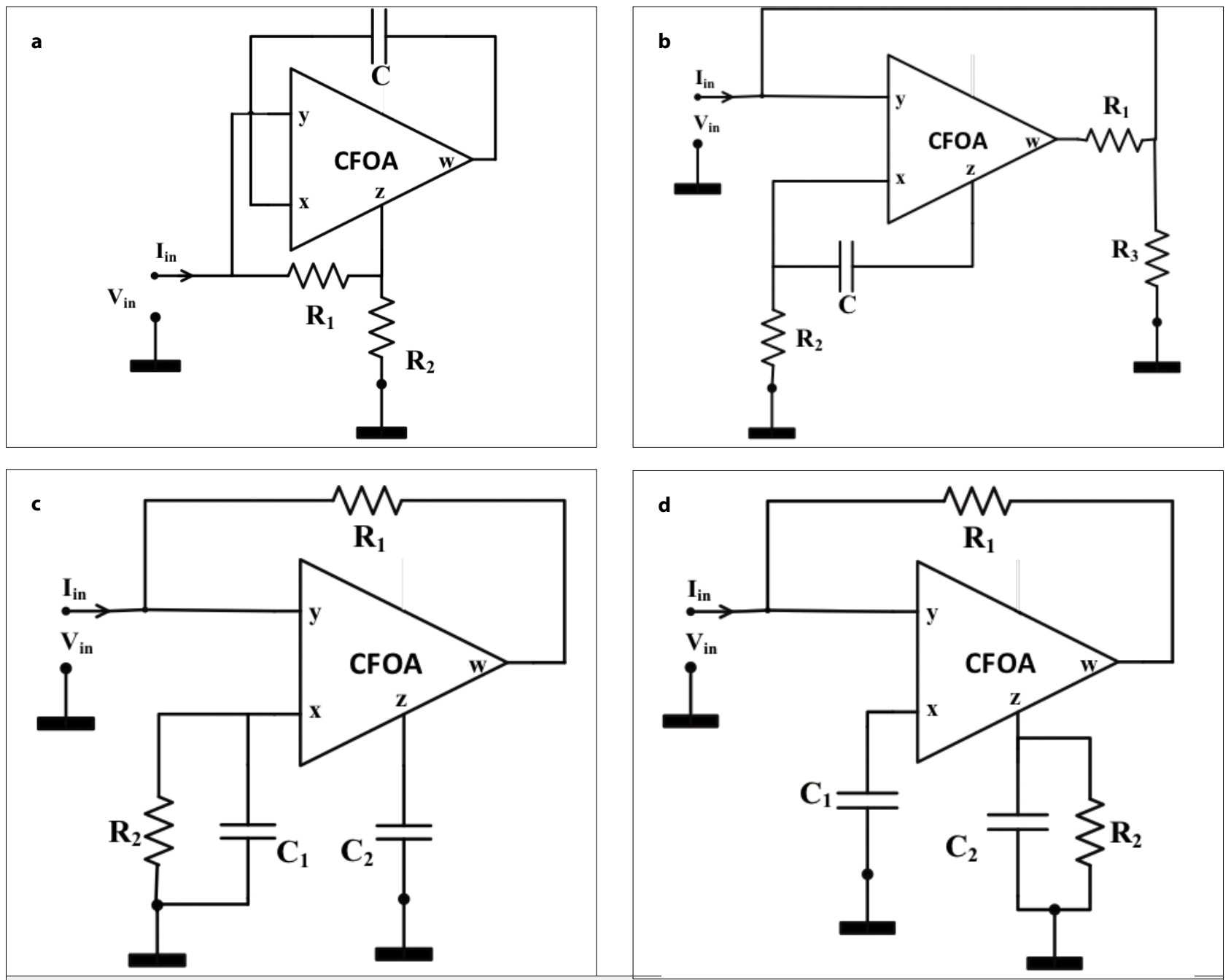

Figure 2. a-d. Proposed inductance simulators made with CFOA

\section{Simulation Results}

As long as higher value inductances occupy a bigger area in chips, Inductor will be a central ingredient in deciding the total chip area because higher inductance values imply larger area consumption. In order to solve this problem, it is more convenient to use active implementations of an inductor which offer less area consumption.

LTSpice program is used to explain the performance of the presented inductance simulator. The simulated frequency response of input impedance for the inductor simulator is given in Figure 2b. The magnitude of impedance of the presented inductance simulator is given in Figure 3. The inductive characteristic extends from $1 \mathrm{kHz}$ to $50 \mathrm{MHz}$.

RLC filter is presented as an application example to demonstrate the performance of the presented inductance simulator. Inductance simulator with a parallel capacitor and resistor formed as a resonant circuit shown in Figure 4. In this Figure actively simulated induc-

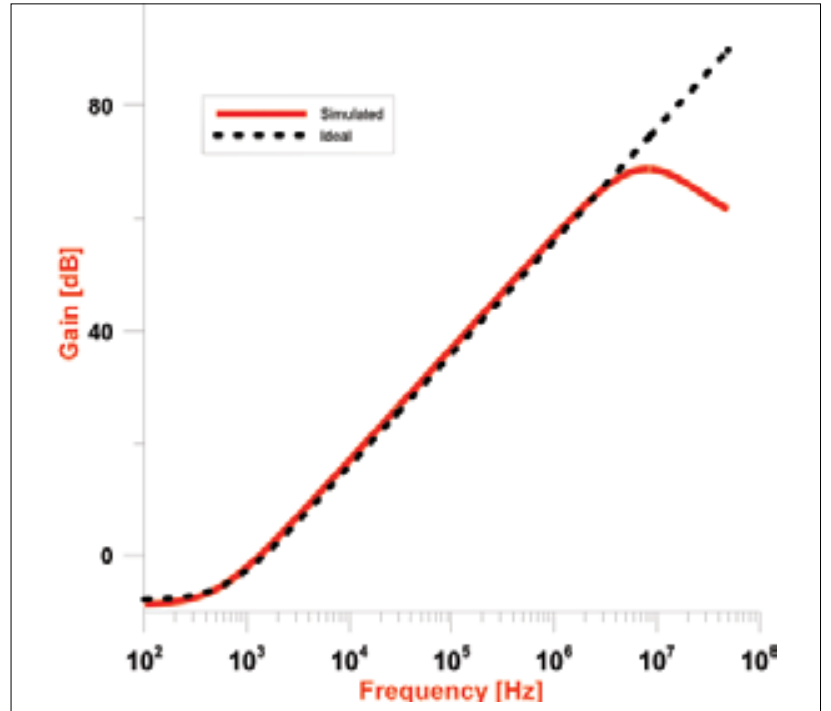

Figure 3. Simulated magnitudes of impedance of presented inductance simulator in comparison with ideal inductance 

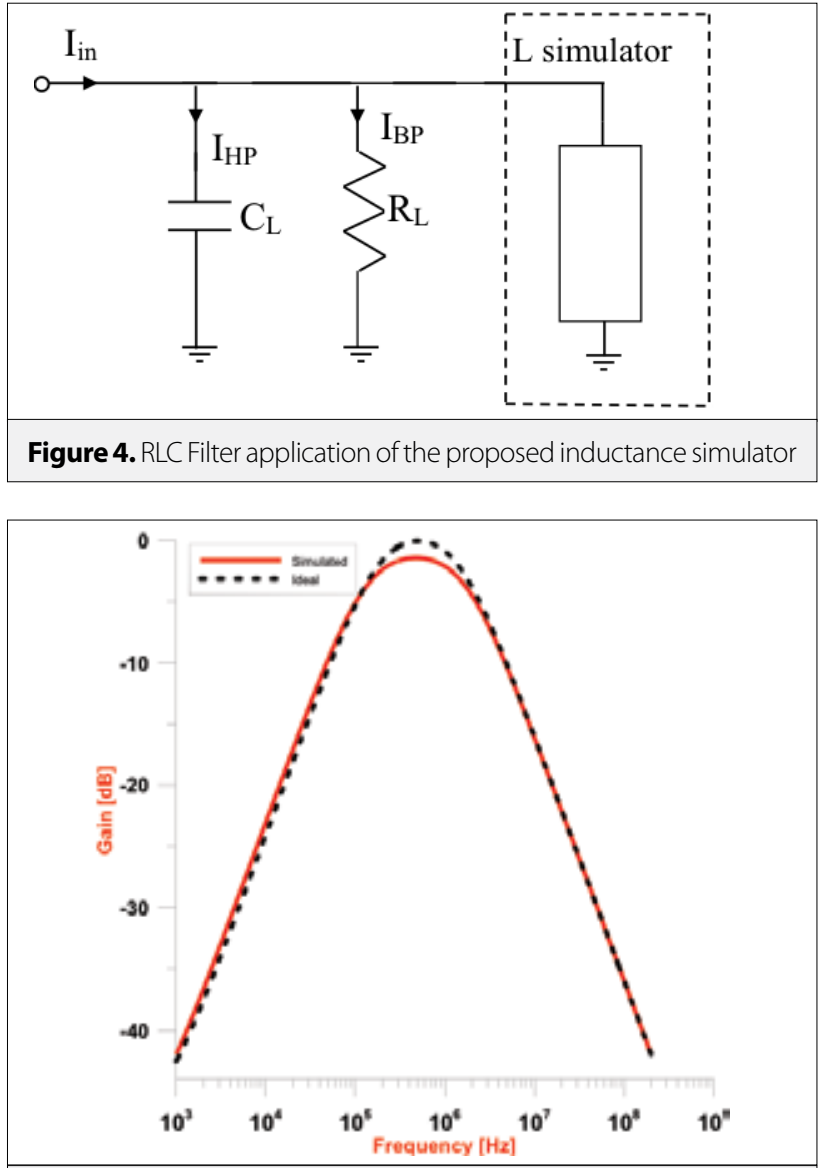

Figure 5. Simulated bandpass response of the filter

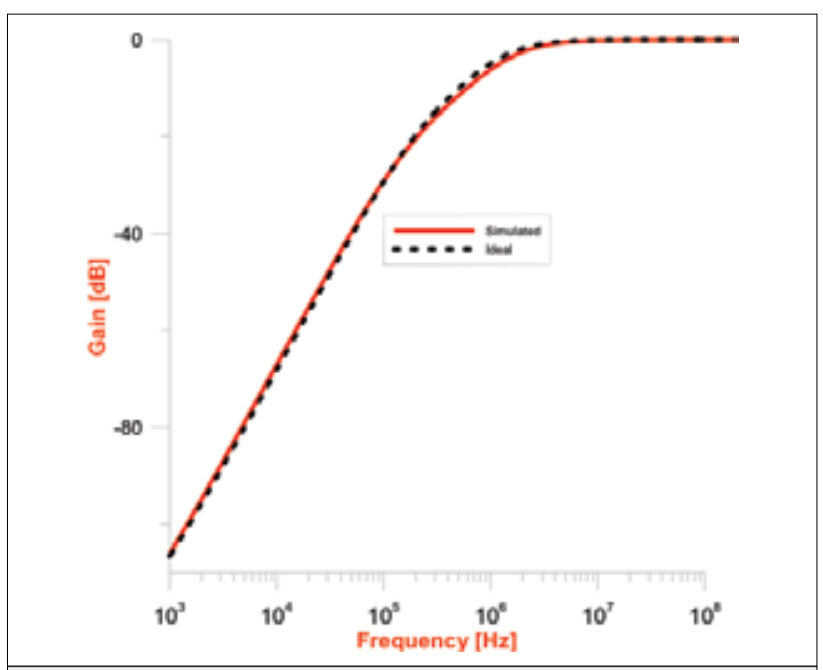

Figure 6. Simulated highpass response of the filter

tance simulator circuit in Figure $2 \mathrm{~b}$ replaces the parallel inductor. The transfer functions are given by the following equations:

$$
\frac{I_{H P}}{I_{i n}}=\frac{s^{2}}{s^{2}+\frac{G_{L}}{C_{L}} s+\frac{1}{L_{e q} C_{L}}}
$$

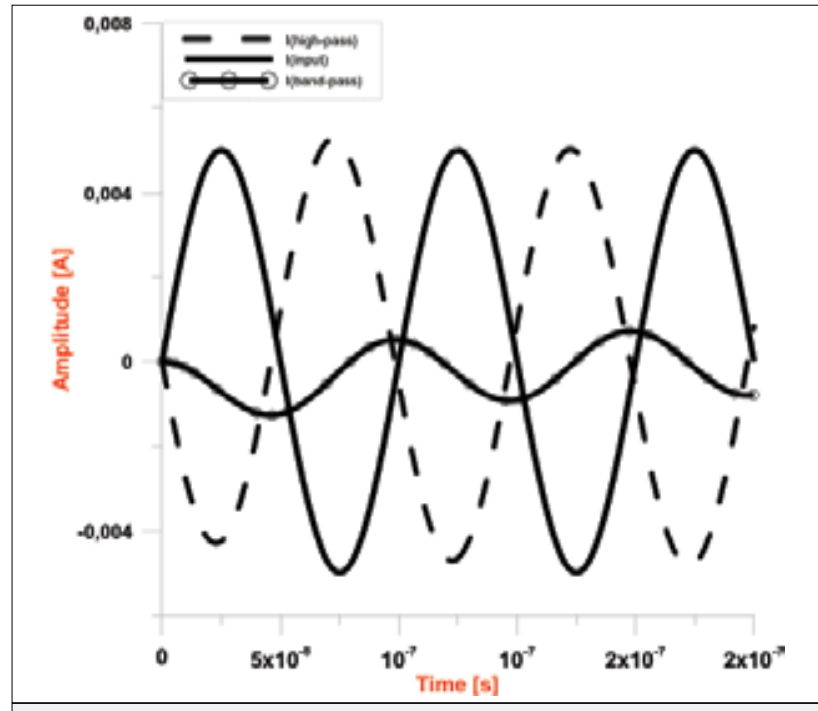

Figure 7. Time domain response of RLC filter high-pass and bandpass filter for $10 \mathrm{~mA}$ peak-to-peak $10 \mathrm{MHz}$ sine wave input

$\frac{I_{B P}}{I_{i n}}=\frac{\frac{G_{L}}{C_{L}} s}{s^{2}+\frac{G_{L}}{C_{L}} s+\frac{1}{L_{e q} C_{L}}}$

The realized filter is simulated with LTSpice program using AD844. Supply voltages are taken as $\mathrm{V}_{\mathrm{DD}}=12 \mathrm{~V}$ and $\mathrm{V}_{\mathrm{SS}}=-12 \mathrm{~V}$. Simulation result of the filter responses, very good agreement with the predicted theory, is given in Figure 5 and Figure 6 respectively. The component values of the accomplished filter are chosen as follows: $\mathrm{C}_{\mathrm{L}}=1 \mathrm{nF}, \mathrm{R}_{\mathrm{L}}=100 \Omega \mathrm{R}_{1}=\mathrm{R}_{2}=\mathrm{R}_{3}=1 \mathrm{k} \Omega$ and $\mathrm{C}=50 \mathrm{pF}$, thus an inductor $\mathrm{L}_{\mathrm{e}}$ $q=100 \mu \mathrm{H}$ is obtained. In order to analysis time responses of RLC filter, peak-to-peak $10 \mathrm{~mA}$ and $10 \mathrm{MHz}$ sinusoidal inputs are applied. The time domain analysis result is given in Figure 7 for bandpass and highpass filter configuration for the circuit in Figure 4.

\section{Conclusions}

In this study, A CFOA based inductor simulators are proposed. The proposed circuit consisted only one single of CFOA, and three or four passive components. The aim of the present research was to propose the inductance simulators which consists three or four passive components in addition to single active device named CFOA. In order to show the effectiveness of the proposed inductance simulators, LTSpice simulation tests were put into practice. This study sets out provide the further possibilities to the designers in the realization of analog integrated circuits such as filters and oscillator applications.

\section{References}

1. P. Soni, B. P. Singh, and M. Bhardwaj, "Design of OTA based floating inductor," in 2011 International Conference on Devices and Communications, ICDeCom 2011 - Proceedings, 2011. [CrossRef]

2. R. Banchuin, B. Chipipop, and B. Sirinaovakul, "Novel practically applicable passive equivalent circuit model of the alternatively structured higher performance practical OTA-based floating inductor," in 2007 International Symposium on Intelligent Signal Processing and Communications Systems, ISPACS 2007 - Proceedings, pp. 447-450, 2008. 
3. R. Banchuin, R. Chaisricharoen, B. Chipipop, and B. Sirinaovakul, "In depth analysis of the CMOS OTA-based floating inductors," in 2006 International Symposium on Intelligent Signal Processing and Communications, ISPACS'06, pp. 239-242, 2007.

4. U. Çam, F. Kaçar, O. Cicekoglu, H. Kuntman, and A. Kuntman, “Novel two OTRA-based grounded immitance simulator topologies," Analog Integr. Circuits Signal Process., vol. 39, no. 2, pp. 169-175, 2004. [CrossRef]

5. B. C. Nagar, S. K. Paul, "Negative inductance simulator using OTRA," vol. 3, no. 2, pp. 2-4, 2016. [CrossRef]

6. F. Kaçar and H. Kuntman, "CFOA-based lossless and lossy inductance simulators," Radioengineering, vol. 20, no. 3, pp. 627-631, 2011.

7. O. Çiçekoğlu, "Precise simulation of immittance functions using the CFOA," Microelectronics J., vol. 29, no. 12, pp. 973-975, Dec. 1998. [CrossRef]

8. M. T. Abuelma'Atti, S. K. Dhar, "CFOA-based floating negative inductance, positive frequency dependent resistance and resistance-controlled capacitance and resistance emulator," Int. Conf. Electron. Information, Commun. ICEIC 2016, pp. 3-5, 2016.

9. M. Taher, "A New CFOA-Based Low Frequency Lowpass Filter for Biomedical Applications," pp. 1-4, 2016.

10. M. Taher, "New CFOA-Based Floating Lossless Negative Immittance Function Emulators," pp. 0-3, 2015.

11. M. T. Abuelma'atti, "New grounded immittance function simulators using single current feedback operational amplifier," Analog Integr. Circuits Signal Process., vol. 71, no. 1, pp. 95-100, 2012. [CrossRef]

12. E. Yuce, "Novel lossless and lossy grounded inductor simulators consisting of a canonical number of components," Analog Integr. Circuits Signal Process., vol. 59, pp. 77-82, 2009. [CrossRef]

13. J. K. Pathak, A. K. Singh, R. Senani, "New canonic lossy inductor using a single CDBA and its application," Int. J. Electron., vol. 103, no. 1, pp. 1-13, 2016. [CrossRef]

14. S. Minaei, E. Yuce, "A simple CMOS-based inductor simulator and frequency performance improvement techniques," AEU - Int. J. Electron. Commun., vol. 66, no. 11, pp. 884-891, 2012. [CrossRef]

15. U. Çam, O. Çiçekoğlu, H. Kuntman, "Novel lossless floating immitance simulator employing only two FTFNs," Analog Integr. Circuits Signal Process., vol. 29, no. 3, pp. 233-235, 2001. [CrossRef]

16. O. Channumsin, J. Pimpol, C. Thongsopa, W. Tangsrirat, "VDBA-based floating inductance simulator with a grounded capacitor," in Proceedings - 2015 7th International Conference on Information Technology and Electrical Engineering: Envisioning the Trend of Computer, Information and Engineering, ICITEE 2015, 2015, pp. 114-117. [CrossRef]
17. A. Yeşil, F. Kaçar, K. Gürkan, "Lossless grounded inductance simulator employing single VDBA and its experimental band-pass filter application," AEU-Int.J. Electron. Commun., vol. 68, no. 2, pp. 143-150, 2014. [CrossRef]

18. A. Yesil and F. Kacar, "VDBA-based lossless and lossy inductance simulators and its filter applications," in 2016 24th Signal Processing and Communication Application Conference (SIU), 2016, pp. 909-912. [CrossRef]

19. A. Abaci and E. Yuce, "Modified DVCC based quadrature oscillator and lossless grounded inductor simulator using grounded capacitor(s)," AEU - Int. J. Electron. Commun., vol. 76, pp. 86-96, 2017. [CrossRef]

20. E. Yuce, O. Cicekoglu, S. Minaei, "CCIl-based grounded to floating immittance converter and a floating inductance simulator," Analog Integr. Circuits Signal Process., vol. 46, no. 3, pp. 287-291, 2006. [CrossRef]

21. G. Ferri, N. Guerrini, E. Silverii, A. Tatone, "Vibration damping using CCII-based inductance simulators," IEEE Trans. Instrum. Meas., vol. 57, no. 5, pp. 907-914, 2008. [CrossRef]

22. A. Yeşil and F. Kaçar, "New dxccii-based grounded series inductance simulator topologies," İstanbul Univ. - J. Electr. Electron. Eng., vol. 14, no. 2, pp. 1785-1789, 2015.

23. I. Myderrizi, S. Minaei, E. Yuce, "DXCCIl-based grounded inductance simulators and filter applications," Microelectronics J., vol. 42, no. 9, pp. 1074-1081, 2011. [CrossRef]

24. B. Metin, "Supplementary inductance simulator topologies employing single DXCCII," Radioengineering, vol. 20, no. 3, pp. 614618, 2011.

25. M. Incekaraoglu and U. Çam, "Realization of Series and Parallel R-L and C-D Impedances Using Single Differential Voltage Current Conveyor," Analog Integr. Circuits Signal Process., vol. 43, no. 1, pp. 101-104, Apr. 2005. [CrossRef]

26. E. Yuce, "Comment on'realization of series and parallel R-L and C-D impedances using single differential voltage current conveyor,"' Analog Integr. Circuits Signal Process., vol. 49, no. 1, pp. 91-92, 2006. [CrossRef]

27. H. Y. Wang and C.T. Lee, "Systematic synthesis of R-L and C-D immittances using single CCIII," Int. J. Electron., vol. 87, no. December 2011, pp. 293-301, 2000.

28. H. Y. Wang and C. T. Lee, "Realisation of R-L and C-D immittances using single FTFN," Electron. Lett., vol. 34, no. 6, p. 502, 1998. [CrossRef]

29. M. O. Cicekoglu, "Active simulation of grounded inductors with CCII's and grounded passive elements," Int. J. Electron., vol. 85, no. 4, pp. 455-462, 1998. [CrossRef]

30. E. Yuce and S. Minaei, "A modified CFOA and its applications to simulated inductors, capacitance multipliers, and analog filters," IEEE Trans. Circuits Syst. I Regul. Pap., vol. 55, no. 1, pp. 266-275, 2008. [CrossRef]

31. O. Çiçekolu, A. Toker, and H. Kuntman, "Universal immittance function simulators using current conveyors," Comput. Electr. Eng., vol. 27, no. 3, pp. 227-238, 2001. [CrossRef]

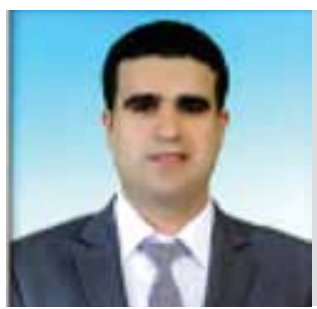

Muhammed Emin Başak received his B.Sc., M.Sc., and Ph. D. degrees from İstanbul University in all in Electrical and Electronics Engineering 2005, 2008, 2014, respectively. Başak has performed research from 2007 to 2008 in I'ESIGELEC, IRSEEM Institutes, Rouen, France. He is currently an Assistant Professor at Faculty of Naval Architecture and Maritime at the Yıldız Technical University. His general research interests modelling, simulation of electronic devices and electronic circuits.

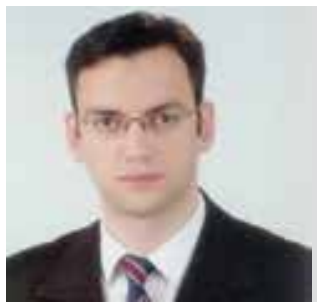

Fırat Kaçar received his B.Sc., M.Sc. and Ph.D. degrees from İstanbul University in all in Electrical and Electronics Engineering 1998, 2001 and 2005. He is currently Professor at the Electrical and Electronics Engineering Department of İstanbul University. His current research interests include analog circuits, active filters, synthetic inductors; CMOS based circuits' electronic device modeling and hot-carrier effect of MOS transistors. He is the author or co-author of about 80 papers published in scientific journals or conference proceedings. 